\title{
EL CAMINO BRASILEÑO HACIA EL RECONOCIMIENTO DEL DERECHO Y LA JURISDICCIÓN INDÍGENA
}

\section{THE BRAZILIAN PATHWAY TOWARDS THE RECOGNITION OF THE INDIGENOUS LAW AND JURISDICTION}

\section{O PERCURSO BRASILEIRO RUMO AO RECONHECIMENTO DO DIREITO E DA JURISDIÇÃO INDÍGENA}

\author{
Eduardo Manuel Val* \\ Dalton Robert Tiburcio* * \\ Denise de Almeida Guimarães***
}

1 Introducción. 2 El paso del "integracionismo" al pluralismo étnico y cultural. 3 El enfoque del Derecho Internacional Público. 4 Derechos colectivos de los pueblos indígenas y el Derecho a la autodeterminación. 5 La baja efectividad del modelo fundado en el multiculturalismo liberal. 6 Las resistencias al reconocimiento de la existencia del Derecho Indígena. 7 El reconocimiento del Derecho Indígena y el ejercicio de su jurisdicción. 8 Conclusiones. Referências.

\section{RESUMEN}

El reconocimiento jurídico del derecho y de la jurisdicción indígena, a partir del análisis de la transición del paradigma integracionista al pluralismo étnico y cultural, es tema aún no consolidado en la comunidad jurídica brasileña. Así, este artículo se propone investigar dicho cambio y su repercusión en las normas de derecho internacional y en algunas Constituciones latinoamericanas, notablemente, la Constitución brasileña de 1988. Aunque el orden institucional brasileño aún no ha consolidado los parámetros del multiculturalismo liberal, estando al margen del constitucionalismo plurinacional, el texto investiga las posibilidades

* Doutor e Mestre em Direito pela Pontifícia Universidade Católica do Rio de Janeiro. Professor permanente do Programa de Pós-graduação stricto sensu em Direito Constitucional da Universidade Federal Fluminense em Niterói/RJ e do Programa de Pós-graduação stricto sensu em Direito da Universidade Estácio de Sá, no Rio de Janeiro. Rio de Janeiro, RJ, Brasil. E-mail: <eduardval11@hotmail.com>.http://orcid.org/0000-0002-3462-3615

** Doutorando em Direito pela Universidade Federal do Rio de Janeiro. Mestre em Direito Constitucional pela Universidade Federal Fluminense. Especialista em Advocacia Pública pela Universidade do Estado do Rio de Janeiro. Rio de Janeiro, RJ, Brasil. E-mail: <daltonrobert2014@gmail.com>. http://orcid.org/00000002-3594-279X

*** Doutoranda em Direito pela Universidade Federal do Rio de Janeiro. Mestre em Direito Constitucional pela Universidade Federal Fluminense. Especialista em Direito e Processo do Trabalho pela UCAM. Professora universitária. Rio de Janeiro, RJ, Brasil. E-mail: < dealgui@hotmail.com>. http://orcid.org/0000-0002-3261-4248 
de hacer efectivo el pluralismo étnico. La acogida del derecho consuetudinario indígena y del ejercicio de la jurisdicción indígena materializa sustancialmente el pluralismo étnico garantizado por la norma constitucional al reconocer a los indios su organización social, sus costumbres y sus tradiciones. El método de abordaje desarrollado será la investigación bibliográfica en doctrina, con destaque para la producción latinoamericana.

Palabras clave: Derecho indígena. Jurisdicción indígena. Pluralismo jurídico. Autodeterminación. Multiculturalismo.

\begin{abstract}
The legal recognition of indigenous law and jurisdiction has not yet been consolidated in the Brazilian legal community. Thus, this article proposes to investigate the transition from the integrationist paradigm to that of ethnic and cultural pluralism and its repercussion in the norms of international law and in some Latin American Constitutions, notably the Brazilian Constitution of 1988. Although the Brazilian institutional order has not even consolidated the parameters of liberal multiculturalism, being on the fringes of pluri-national constitutionalism, the text investigates the possibilities of the realization of ethnic pluralism. The acceptance of indigenous customary law and of the exercise of indigenous jurisdiction substantially materializes the ethnic pluralism guaranteed by the constitutional norm that recognizes the social organization, customs and traditions of indigenous peoples. The papers will use the bibliographical research, especially with Latin American production.
\end{abstract}

Keywords: Indigenous Law. Indigenous jurisdiction. Legal pluralismo. Self-determination. Multiculturalism.

\title{
RESUMO
}

O reconhecimento jurídico do direito e da jurisdição indígena é tema ainda não consolidado na comunidade jurídica brasileira. Assim, este artigo se propõe a investigar a transição do paradigma integracionista para o do pluralismo étnico e cultural e sua repercussão nas normas de direito internacional e em algumas Constituições latino-americanas, notadamente a Constituição brasileira de 1988. Embora a ordem institucional brasileira ainda não tenha sequer consolidado os parâmetros do multiculturalismo liberal, estando à margem do constitucionalismo plurinacional, o texto investiga as possibilidades de efetivação do pluralismo étnico. $\mathrm{O}$ acolhimento do direito consuetudinário indígena e do exercício da jurisdição indígena materializa substancialmente o pluralismo étnico garantido pela norma constitucional que reconhece aos povos indígenas sua organização social, seus costumes e suas tradições. $O$ artigo utiliza a pesquisa bibliográfica, especialmente da produção literária latino-americana. 
Palavras-chave: Direito indígena. Jurisdição indígena. Pluralismo jurídico. Autodeterminação. Multiculturalismo.

\section{INTRODUCCIÓN}

En el interior de la Catedral de Cusco, en el Perú, en la Iglesia del Triunfo, hay una escultura del apóstol Santiago empuñando una espada y montado en un caballo blanco, bajo cuyas patas hay un hombre con apariencia mora, pero con vestimentas que insinúan si se trata de un indígena americano. Una pintura que se encuentra en la misma Iglesia retrata al santo en su caballo, pisoteando los hombros de incas, en una representación del "milagro de Sunturhuasi". Se trata de una leyenda difundida por los españoles sobre la guerra de la reconquista de Cusco, lanzada en 1536 por Manco Inca contra los invasores. Narra la leyenda que en el momento en que los españoles parecían derrotados, recogidos en el recinto sagrado de Inca Suntur Wasi, ocurrió una aparición de la Virgen María. En apoyo a los conquistadores, también descendió de los cielos el apóstol Santiago cabalgando y matando a los indios Quechua. En la memoria de la derrota del pueblo Inca fue erigida, en el ala izquierda de la actual catedral de Cusco, la "Iglesia del Triunfo" (BRUNN, 2009, p. 11).

La difusión de esta historia, como mecanismo de imposición de la derrota a los nativos, hizo la imagen del santo, conocido en España como Santiago Mata-moros - como consecuencia de las leyendas medievales que relatan apariciones del militar de Cristo en las batallas de los reyes católicos contra los árabes, por la reconquista de la península ibérica -, ser denominada en América de Santiago Mata-incas o Santiago Mata-indios. Lo curioso es que, por el sincretismo religioso propio de los países andinos, Santiago, el apóstol - llamado por Jesús "hijo del trueno" - pasó a ser asociado a la figura de Illapa, el dios del trueno. En América, Santiago es también Illapa; de este mismo modo, María tiene algo de Pachamama (la Madre Tierra o la Montaña). Esta fusión de los símbolos religiosos muestra que ambas culturas - la europea y la de los pueblos originarios - sufrieron transformaciones tras el enfrentamiento violento provocado por el proceso de colonización.

Los efectos devastadores del pasado de dominación se reflejan en la catastrófica disminución demográfica de las poblaciones indígenas. Los indígenas americanos fueron sometidos al exterminio genocida, a la esclavización y a la catequización en la era colonial, también al etnocidio (política deliberadamente tendente a destruir la identidad étnica y cultural de un pueblo y su posibilidad de reproducirse como tal) promovido por las medidas integracionistas de los Estados latinoamericanos independientes (STAVENHAGEN, 2010).

En Brasil, los cómputos más aceptados indican que en el año 1500 la población indígena estimaba alrededor de dos a cinco millones, en un total de 1400 pueblos indígenas. En los últimos años, se han conocido, en Brasil, 225 pueblos indígenas con una población aproximada de 600.000 personas, equivalente al 0,3\% de la población brasileña (KAYSER, 2010, p. 48). 
La organización social y el patrimonio cultural de los pueblos indígenas, tanto en Brasil como en otros países de América Latina, no desaparecieron. Los derechos colectivos de los pueblos indígenas son un elemento común del Constitucionalismo latinoamericano, que ha recibido distintas respuestas a lo largo del tiempo y del espacio. Entre las diversas cuestiones sociales y ambientales involucradas, el reconocimiento de la existencia del derecho indígena y el ejercicio de su jurisdicción por las propias comunidades indígenas todavía son presentadas como tabú para el pensamiento jurídico brasileño forjado en el paradigma del monismo estatal.

Una visión conservadora basada en la ficción del Estado nación homogéneo sigue prevaleciendo en las instituciones jurídicas brasileñas. Esta ficción de la única nación brasileña, constituida por un solo pueblo mestizo, rechaza el reconocimiento de la pluralidad étnica y cultural de la sociedad y la existencia de diversos pueblos y naciones en el territorio que abarca el Estado brasileño (DANTAS, 2017). Este artículo pretende romper la visión conservadora de las instituciones jurídicas brasileñas y defender el reconocimiento del derecho y la jurisdicción indígena. Al apostar por las posibilidades emancipatorias de la doctrina jurídica (SCHIER, 1999, p. 39), el artículo busca demostrar, partiendo del sistema constitucional, las normas del derecho internacional y el derecho infraconstitucional brasileño, que la resistencia a la aceptación del derecho y la jurisdicción indígena tiene una base ideológica y no jurídica.

Por lo tanto, el objetivo central de este artículo es presentar el recorrido brasileño que permite el reconocimiento de la identidad jurídico-cultural de los pueblos indígenas. Partiendo desde la transición del integracionismo del Estado nación hacia el modelo del pluralismo étnico, caracterizamos el escenario actual de baja efectividad del modelo fundado en el parámetro liberal del multiculturalismo. Contrastamos esta etapa con las visiones fundadas en el interculturalismo de las nuevas experiencias latinoamericanas basadas en el estado plurinacional.

La fundamentación teórico-conceptual del trabajo investigará cómo los cambios de los paradigmas fueron descriptos en las Constituciones latinoamericanas y en las normas de derecho internacional. A partir del análisis de la Constitución de la República Federativa del Brasil de 1988, este artículo buscará aún demostrar la juridicidad del reconocimiento del derecho y de la jurisdicción indígena como forma de concreción del pluralismo étnico que subyace al texto constitucional. El método de abordaje desarrollado será la investigación bibliográfica en doctrina, con destaque para la producción literaria latinoamericana.

\section{EL PASO DEL “INTEGRACIONISMO” AL PLURALISMO ÉTNICO Y CULTURAL}

La independencia de las antiguas colonias españolas y portuguesas de Latinoamérica consolidó la ideología de la unidad nacional frente a las importaciones del modelo liberal europeo del Estado-nación. La identificación entre Estado y Nación hizo que la voluntad 
del grupo social o cultural poseedor del Estado pasara a ser interpretada como la voluntad de la sociedad en su conjunto (BARTOLOMÉ; BARABAS, 1998).

Todo ello representó para las sociedades alternativas, comprendidas dentro de las jurisdicciones políticas de los Estados latinoamericanos - como eran el caso de las indígenas - no solamente una dominación política, sino también social y cultural. Este dato histórico genera el origen de la adopción, por los países americanos que agregan poblaciones indígenas, de una política oficial de integración del indígena a la cultura nacional. Aunque existan antecedentes del indigenismo oficial desde el siglo XIX, el registro formal de esa política integracionista en América fue el Primer Congreso Indigenista Interamericano celebrado en la ciudad de Pátzcuaro, México, en 1940 (CABEDO MALLOL, 2002, p. 31).

En Brasil, el objetivo integracionista ${ }^{1}$, presente en casi todas sus Constituciones desde 1934, exceptuando la Constitución de 1937, está precisamente demostrado en el texto de la Constitución de 1967 y su Enmienda Constitucional el 1 de 1969, que establecía ser de la competencia de la Unión legislar sobre la "incorporación de los silvícolas a la comunión nacional" (artículo 8, inciso XVII, inciso "o").

El abandono del integracionismo, desde la perspectiva de la historia brasileña, es referido por Kayser (2010, p. 209-210), a partir del importante trabajo realizado desde los años 1940, por los hermanos Orlando, Claudio y Leonardo Villas Boas, que iniciaron y ordenaron el Parque Nacional del Xingu, fundado en 1961. Los hermanos Villas Boas, desde hace mucho, "defendían el punto de vista de que las culturas indígenas merecen reconocimiento y que los indígenas pueden sobrevivir sólo con sus propias culturas" (KAYSER, 2010, p. 209-210). El autor también destaca el testimonio del "sertanista" de la Fundación Nacional del Indio (FUNAI), Apoena Meireles, sobre la expedición de 1969 para contactar a los indios Suruí, hasta el entonces aislados. Meireles, tras la expedición, declaró que haría todo lo posible para posponer el contacto con un grupo primitivo, ya que se había convencido de que "no tenemos nada que ofrecerles, excepto su propio exterminio a medio, o hasta mismo, a corto plazo" (KAYSER, 2010, p. 209-210).

El gran cambio, sin embargo, ocurre debido al movimiento realizado a partir de la segunda mitad del siglo XX, a partir de "un esfuerzo de los pueblos [indígenas] con la intención de construir unidades, alianzas y organizaciones capaces de reivindicar y luchar por derechos, construida una unidad indígena estructurada en organizaciones nacionales"

1 La creación, en 1910, del Servicio para la Protección de los Indígenas y la Localización de Trabajadores Nacionales (SPILTN) ya indicaba el objetivo de integrar al indígena en la nación, ya sea como trabajador rural o como guardia de fronteras, bajo la influencia del postulado positivista de presentar el progreso a las poblaciones nativas (RODRIGUES, 2019, p. 185-203). En cualquiera de los casos, entre los años cuarenta y cincuenta surgieron visiones alternativas, basadas en los objetivos de preservación ambiental y aculturación gradual (LIMA, 1992, p. 168-170).

2 "Sertanista" era la designación de un cargo del cuerpo de funcionarios de la FUNAI. El término está ligado a la tradición colonial de ocupación del interior de Brasil: el "sertão". La nomenclatura actual de cargo equivalente de la estructura de la FUNAI es "Indigenista Especializado", que mejor se adecua a las nuevas concepciones de la antropología. 
(SOUZA FILHO, 2017, p. 204). El movimiento indígena, a partir de los años 70 del siglo $\mathrm{XX}$, intensificó las reivindicaciones que llevaron al paso del indigenismo oficial - que pretendía la integración del indígena a la nación a la que pertenece - al indigenismo participativo, que lucha por el reconocimiento del derecho a la diferencia cultural (CABEDO MALLOL, 2002, p. 30-34). El reconocimiento jurídico de los derechos colectivos de los pueblos indígenas, en especial el respeto a su cultura, refleja la consolidación del concepto antropológico de relativismo cultural, según el cual es imposible comparar las sociedades y las culturas entre ellas, considerando la peculiaridad singularidad de cada una (KAYSER, 2010, p. 210-211).

Actualmente, casi todas las Constituciones de países latinoamericanos que engloban poblaciones indígenas reconocen el pluralismo étnico y cultural, ya sea de forma explícita o inferida de su contexto. Las excepciones son las Constituciones de Chile y Costa Rica, que no contemplan la cuestión indígena; también la de El Salvador, país en el que la referencia es simbólica e indirecta, y la de Honduras, cuya referencia es restricta y de aspecto únicamente proteccionista. Las Constituciones de Nicaragua, Colombia, Ecuador, Bolivia, Perú, Guatemala, México y Venezuela constituyen un grupo en el cual, en sus artículos iniciales, se expresa el pluralismo étnico y cultural, incluido en el título correspondiente a los principios fundamentales o disposiciones generales o en el título dedicado a la persona o a las garantías individuales (CABEDO MALLOL, 2002, p. 42). En el contexto de los países sudamericanos que expresamente legitiman el pluralismo étnico, se destaca la Constitución de Bolivia, aprobada en plebiscito en el año 2009, construida acerca de la plurinacionalidad (OLIVEIRA FILHO, 2016, p. 31-37).

La Constitución brasileña de 1988, la primera a dedicarle al derecho de los indios un capítulo propio (VIII), dejó de referirse a la "incorporación de los silvícolas a la comunión nacional", como presuponía la Constitución de 1967. Esa ausencia de referencia tanto a la incorporación como la mención del término "silvícola" no es un simple error de redacción, sino el claro deseo de tomar como base la "moderna teoría de la relatividad cultural [y] desistir definitivamente del objetivo de incorporación de los indios a la sociedad nacional" (KAYSER, 2010, p. 214). El pluralismo étnico es el valor subyacente al art. 231, caput, de la Constitución brasileña de 1988, que reconoce a los indios su organización social, costumbres, lenguas, creencias y tradiciones. El pluralismo étnico también se manifiesta en otros dispositivos constitucionales, tales como los contenidos en los artículos 215, párrafos primero y segundo, 216, caput y 242, párrafo primero de la Constitución Federal. ${ }^{3}$ De este modo,

3 "Art. 215. El Estado garantizará a todos el pleno ejercicio de los derechos culturales y acceso a las fuentes de la cultura nacional, y apoyará y alentará la valorización y la difusión de las manifestaciones culturales. $\S 1^{\circ}$ El Estado protegerá las manifestaciones de las culturas populares, indígenas y afrobrasileñas, y de las de otros grupos participantes del proceso civilizatorio nacional. $\S 2^{\circ}$ La ley dispondrá sobre la fijación de fechas conmemorativas de alta significación para los diferentes segmentos étnicos nacionales. [...]. Art. 216. Constituyen patrimonio cultural brasileño los bienes de naturaleza material e inmaterial, tomados individualmente o en conjunto, portadores de referencia a la identidad, a la acción, a la memoria de los diferentes grupos formadores de la sociedad brasileña, en los que se incluyen: I - las formas de expresión; II - los modos de crear, hacer y vivir; III - las creaciones científicas, artísticas y tecnológicas; IV - las obras, objetos, documentos, edificaciones y 
aunque la Constitución brasileña de 1988 no haya seguido la opción de otras Constituciones latinoamericanas de reconocer categóricamente la diversidad étnica y cultural de la nación, el pluralismo étnico es un valor constitucional implícito.

Los avances jurídico-normativos, sin embargo, no significan la ausencia de obstáculos institucionales y sociales al servicio del comando constitucional. De hecho, como resalta Kayser (2010, p. 478-480), a pesar de la retórica progresista del ordenamiento jurídico brasileño, los derechos colectivos de los pueblos indígenas son aún de baja efectividad, en razón de la resistencia de grupos económicos y de la falta de el compromiso de los Poderes Públicos en concretarlos. La vinculación del texto constitucional con el paradigma del multiculturalismo liberal contribuye a este panorama. Aunque la Constitución de 1988 avanzó en el reconocimiento de la diversidad cultural, la ausencia de derechos políticos colectivos para los pueblos indígenas, como en otros contextos constitucionales sudamericanos, inhibe la consolidación de los derechos de los pueblos originarios. ${ }^{4}$

\section{EL ENFOQUE DEL DERECHO INTERNACIONAL PÚBLICO}

El cambio de paradigma en el trato de la cuestión indígena también se verifica en el Derecho Internacional Público. El primer instrumento internacional dedicado específicamente a la temática indígena fue la Convención 107, de la Organización Internacional del Trabajo (OIT), sobre la Protección e Integración de las poblaciones indígenas y de otras poblaciones tribales y semi-tribales de los países independientes, adoptada en 1957.

La internalización de la Convención 107 de la OIT al derecho brasileño se dio por medio de su aprobación por el Decreto Legislativo 20 de 1965 y por su promulgación por el Decreto 58.824 de 1966. Pese el reconocimiento de derechos a las poblaciones indígenas (aún, no se utilizó en ese documento el término pueblos indígenas), el objetivo de la referida Convención era el de la integración progresiva de los indígenas a sus respectivas colectividades. Así figuraba el artículo dos de la citada Convención que las poblaciones podrían conservar sus costumbres e instituciones que no fueran incompatibles con el sistema jurídico nacional o los objetivos de los programas de integración.

El espíritu integracionista de la Convención 107 era notorio, ya que su objetivo, el

demás espacios destinados a las manifestaciones artístico-culturales; $\mathrm{V}$ - los conjuntos urbanos y sitios de valor histórico, paisajístico, artístico, arqueológico, paleontológico, ecológico y científico. [...]. Art. 242. [...] § $1^{\circ} \mathrm{La}$ enseñanza de la Historia de Brasil tendrá en cuenta las contribuciones de las diferentes culturas y etnias para la formación del pueblo brasileño." (BRASIL, 1988, en línea, traducción nuestra).

4 La edición de la Medida Provisional 870 del 1 de enero de 2019, que, mediante la reorganización de la estructura administrativa de la Administración Pública Federal, pretendía atribuir al Ministerio de Agricultura la competencia para identificar, delimitar, demarcar y registrar las tierras tradicionalmente ocupadas por los pueblos indígenas, retirándola de FUNAI, demuestra la fragilidad del marco institucional sobre la cuestión de la defensa de los derechos de los pueblos indígenas en el Brasil. En este sentido, Palmquist, Araújo Junior, Boaventura, Beckhausen, Zollinger y Oliveira (2019) defienden la inconstitucionalidad de la Medida Provisional 870/2019, por violación del artículo 231 de la Constitución, entre otros razonamientos. 
de incorporar gradualmente al indígena a la comunidad nacional, partió de la suposición de que "el caso de los indígenas consiste en una parte de la comunión nacional inferior, de poco valor, en una etapa transitoria de evolución, que debe superarse lo más rápidamente posible para el bienestar de los indígenas" (KAYSER, 2010, p. 333).

Como consecuencia de la presión de las organizaciones indígenas de los Estados miembros de la OIT, se adoptó en 1989 la Convención 169 sobre los pueblos indígenas y tribales en países independientes. La internalización de la Convención 169 de la OIT al derecho brasileño se la efectuó mediante su aprobación por el Decreto Legislativo 143 de 2002 y por su promulgación por el Decreto 5.051 de 2004. Es importante destacar que, a diferencia de la Declaración de las Naciones Unidas sobre los Derechos de los Pueblos Indígenas, que tiene rasgos solamente políticos, la Convención 169 de la OIT establece obligaciones específicas a los países signatarios y pasa a valer en Brasil, tras su internalización, con fuerza normativa vinculante. Por constituir un legítimo tratado internacional de derechos humanos se puede afirmar que la referida Convención es norma supra-legal, en el ámbito de la jurisprudencia del Supremo Tribunal Federal (BRASIL, 2009).

El preámbulo de la Convención 169 de la OIT expresamente revela la adhesión al relativismo cultural, con el objetivo de eliminar la orientación para la asimilación constante de las normas anteriores. Así, establece el artículo 5, "a" e "b" de la Convención, que deberán ser reconocidos y protegidos los valores y prácticas sociales, culturales, religiosas y espirituales propios de los pueblos mencionados y deberá ser considerada la naturaleza de los problemas que les sean presentados, colectiva e individualmente y seguir respetando la integridad de los valores, de las prácticas y de las instituciones de esos pueblos.

Desde el final de la Primera Guerra Mundial, la comunidad internacional, por medio de la Sociedad de las Naciones y la Conferencia de la Paz de 1919, declaró expresamente la igualdad de todas las personas ante la ley, la igualdad de los derechos civiles y políticos y la seguridad de las minorías (LOPES, 2008, p. 20). Respeto a las Naciones Unidas, se destacan la Convención para la Prevención y la Represión del Crimen de Genocidio, de 1948; la Convención sobre la Eliminación de todas las Formas de Discriminación Racial, de 1965; el Pacto Internacional de Derechos Civiles y Políticos de las Naciones Unidas (PIDCP), de 1966, en particular su artículo 27 (al prever que en los Estados en que haya minorías étnicas, religiosas o lingüísticas, las personas pertenecientes a esas minorías no podrán ser privadas del derecho de tener, junto a otros miembros de su grupo, su propia vida cultural, tampoco de profesar y practicar su propia religión ni utilizar su propia lengua); y la Declaración de los Derechos de los Pertinentes a las Minorías Nacionales o Étnicas, Religiosas y Lingüísticas, de 1992. El Pacto Internacional de Derechos Civiles y Políticos de las Naciones Unidas sólo pudo ser internalizado en Brasil por medio de su aprobación por el Decreto Legislativo 226, de 1991, y por su promulgación por el Decreto 592, de 1992.

Los Estados latinoamericanos resistieron a la adopción del sistema internacional de 
protección a las minorías, bajo la alegación de que no habría en América la presencia de las condiciones que confieren a las agrupaciones humanas las características aptas para considerarlas como minoría étnica, conforme a las conclusiones de la $8^{a}$ Conferencia Internacional Americana, celebrada en Lima, en diciembre de 1938, de igual forma en la Reunión de Consulta de Río de Janeiro de 1942 y en la Conferencia Interamericana de 1945, en la Ciudad de México. En los pilares de este argumento estaba el concepto de que los pueblos indígenas se encontrarían en un nivel de desarrollo tan bajo que no necesitarían protección específica (ACCIOLY; SILVA; CASELLA, 2009, p. 484).

Luego, el reconocimiento, por la Declaración de las Naciones Unidas sobre los Derechos de los Pueblos Indígenas, del derecho de autodeterminación de los pueblos indígenas, en los términos previstos en su artículo 3 (al estipular que los pueblos indígenas tienen derecho a la autodeterminación y que por ese derecho determinan libremente su condición política y buscan libremente su desarrollo económico, social y cultural), lejos de significar la legitimación de movimientos separatistas, representa la afirmación de que "Los pueblos indígenas son igual a todos los demás pueblos" y la acogida, al mismo tiempo, del "derecho de todos los pueblos a ser diferentes, a considerarse diferentes y a ser respetados como tales", según establece el preámbulo de la Declaración.

Considerando la resistencia histórica de los países latinoamericanos en imponer a los pueblos indígenas el concepto de minorías étnicas, es notorio que el PIDCP presupone un derecho individual de las personas pertenecientes a las minorías y no un derecho colectivo de las propias minorías, además de consagrar sólo una obligación negatoria y no una obligación para una acción positiva. Sin embargo, hay en la literatura quien defienda que el artículo 27 del PIDCP "contiene una protección de existencia de las minorías, ya que el contenido de los derechos de las minorías podría fácilmente malograrse por el hecho de que los Estados apartan minorías" (KAYSER, 2010, p. 328).

Por su parte, la Asamblea General de las Naciones Unidas proclamó, el 13 de septiembre de 2007, la Declaración de las Naciones Unidas sobre los Derechos de los Pueblos Indígenas, rompiendo con la visión individualista de los derechos humanos y reconociendo los derechos colectivos de los pueblos indígenas. La Declaración de las Naciones Unidas sobre los Derechos de los Pueblos Indígenas, como ocurre con las resoluciones originadas de las organizaciones internacionales, no es de obligatoriedad de implementación, aunque posea el status de derecho internacional habitual.

En la esfera de la Organización de los Estados Americanos (OEA), tanto la Carta de la OEA de 1948 como la Convención Americana sobre Derechos Humanos de 1969 y el Protocolo Adicional en materia de Derechos Económicos, Sociales y Culturales de 1988 son omisiones en relación a los derechos de los pueblos indios. Sin embargo, ya en el año 1972, la Comisión Interamericana sostuvo la necesidad de que los Estados americanos protejan especialmente a los pueblos indígenas, por razones históricas y de principios morales y humanitarios. La Relatoría sobre Derechos de los Pueblos Indígenas de la OEA fue creada en 
1990, con el objetivo de ocuparse de las violaciones a los derechos humanos de los pueblos indígenas de América, especialmente de aquellos en situación de vulnerabilidad (OEA, 2017). Así, a pesar de la ausencia de expresa previsión de los derechos indígenas en los tratados interamericanos, la Corte Interamericana de Derechos Humanos formó, a lo largo de los años, una jurisprudencia protectora de los derechos colectivos de los pueblos indígenas (SECRETARIA NACIONAL DE JUSTIÇA; COMISSÃO DE ANISTIA; CORTE INTERAMERICANA DE DIREITOS HUMANOS, 2014).

La Comisión Interamericana de Derechos Humanos propuso en 1997 el Proyecto de Declaración Americana sobre los Derechos de los Pueblos Indígenas, que fue aprobado por la Asamblea General sólo en junio de 2016. El tema del derecho y de la jurisdicción de los pueblos indígenas fue tratado en la referida Declaración en la sesión sobre Derechos Organizativos y Políticos, en los siguientes términos:

Artículo XXII. Derecho y jurisdicción indígena

1. Los pueblos indígenas tienen derecho a promover, desarrollar y mantener sus estructuras institucionales y sus propias costumbres, espiritualidad, tradiciones, procedimientos, prácticas y, cuando existan, costumbres o sistemas jurídicos, de conformidad con las normas internacionales de derechos humanos.

2. El derecho y los sistemas jurídicos indígenas deben ser reconocidos y respetados por el orden jurídico nacional, regional e internacional.

3. Los asuntos referidos a personas indígenas o a sus derechos o intereses, en la jurisdicción de cada Estado, serán conducidos de manera tal de proveer el derecho a los indígenas de plena representación con dignidad e igualdad ante la ley. Consecuentemente, tienen derecho sin discriminación, a igual protección y beneficio de la ley, incluso, al uso de intérpretes lingüísticos y culturales. 4. Los Estados incorporarán medidas eficaces, en conjunto con los pueblos indígenas, para asegurar la implementación de este artículo (OEA, 2016, en-linea).

El largo período de negociación para la adopción de la Declaración Americana de los Derechos de los Pueblos Indígenas evidencia la dificultad de construcción de consenso entre los países americanos sobre el tema de los derechos de los pueblos indígenas. ${ }^{5}$

La protección especial que el derecho internacional reclama a los pueblos indígenas se deriva del "hecho de que estos pueblos han sido privados de sus derechos por la inmigración de otros pueblos" (WOLFRUM, 1999, p. 369). La comunidad internacional ha buscado construir un estatuto jurídico mínimo para la protección de estos pueblos, que incluye el reconocimiento de los derechos indígenas y el ejercicio de su jurisdicción, por parte de los propios miembros de los pueblos indígenas.

5 Sin embargo, los países americanos tienen mayor adhesión a las normas internacionales para la protección de los derechos de los pueblos indígenas que los países europeos, africanos y asiáticos. Prueba de ello es que, de los 185 Estados miembros de la OIT, sólo 23 han ratificado el Convenio 169 de la OIT. De estos 23 países ratificantes, 15 son americanos: Argentina, Bolivia, Brasil, Chile, Colombia, Costa Rica, Dominica, Ecuador, Guatemala, Honduras, México, Nicaragua, Paraguay, Perú y Venezuela (ILO, 2019). 


\section{DERECHOS COLECTIVOS DE LOS PUEBLOS INDÍGENAS Y EL DERE- CHO A LA AUTODETERMINACIÓN}

El reconocimiento del pluralismo étnico y cultural permite, por lo tanto, la consagración de nuevos derechos, que son los derechos colectivos de los pueblos indígenas (LEIVAS; RIOS; SCHÄFER; SARTORI JÚNIOR, 2017, p. 314-331). Pueden ser enumerados como tales derechos: el derecho a la identidad cultural indígena; el reconocimiento de sus lenguas; el reconocimiento de los derechos originarios sobre las tierras que tradicionalmente ocupan y sus garantías; el derecho a la participación y a la consulta previa sobre las decisiones que puedan afectar su integridad étnica; el derecho al desarrollo propio; el derecho a la protección del entorno físico y ecológico de las comunidades indígenas; y el derecho a la autodeterminación y a la autonomía.

Kayser (2010, p. 239-250) señala las siguientes garantías constitucionales de los derechos especiales de los indios a la tierra: la prohibición de transferencia y de remoción de grupos indígenas de sus tierras; la prohibición de la actividad de excavación de mineral en territorio indígena; la inalienabilidad, la indisponibilidad e imprescriptibilidad de los derechos sobre las tierras indígenas; la ineficacia jurídica de las infracciones a las prohibiciones del art. 231 de la Constitución brasileña; la obligación de demarcación; la obligación general de protección a los bienes jurídicos indígenas.

El derecho de autodeterminación de los pueblos indígenas fue la gran controversia que retrasó la aprobación de la Declaración de las Naciones Unidas sobre los Derechos de los Pueblos Indígenas, cuyo origen se remonta al año 1970, cuando la Subcomisión de Prevención y Protección de las Minorías inició los estudios del problema de la Discriminación contra las Poblaciones Indígenas. El texto definitivo del proyecto de Declaración fue concluido en 1993, pero su aprobación ocurrió en 2007, tras complementarse con la rectificación expresa de que el derecho de autodeterminación no significa el apoyo a proyectos de independencia de los pueblos indígenas. Esta demanda estuvo atendida por el artículo 46, párrafo primero, de la Declaración, al disponer que nada de lo dispuesto en la Declaración será interpretado como para conferir a un Estado, pueblo, grupo o persona cualquier derecho de participar en una actividad o de realizar un acto contrario a la Carta de las Naciones Unidas; tampoco se lo entenderá como: autorizar o motivar cualquier acción direccionada a desmembrar o a reducir, total o parcialmente, la integridad territorial o la unidad política de Estados soberanos e independientes.

Además, la Convención 169 de la OIT, al utilizar la expresión pueblos indígenas en lugar de la nomenclatura "poblaciones indígenas" antes adoptada por la Convención 107 de la OIT, expresamente advirtió, en su artículo primero, párrafo 3, que el empleo del término "pueblos", en la Convención, no se debe interpretarlo mediante cualquier correlación referente a los derechos que puedan atribuirse a ese término en el Derecho internacional.

En el juicio por el Supremo Tribunal Federal del caso de la demarcación de la reserva 
indígena Raposa Serra do Sol (BRASIL, 2010) esa cuestión fue propuesta en el debate, al analizar la alegación de que la demarcación del área indígena podría alcanzar la autonomía política de la unidad federada. Carlos Ayres Britto, ministro en aquella ocasión, al asegurar que ninguna tierra indígena se eleva al nivel de territorio político o unidad federada, rechazó la utilización del vocablo "pueblos indígenas", ya que, en su opinión, el término expresaría la independencia a nivel internacional de esas agrupaciones humanas. La crítica del ministro Carlos Ayres Britto, sin embargo, desconsideró la cláusula del artículo 46 de la Declaración de las Naciones Unidas sobre los Derechos de los Pueblos Indígenas. En el mismo caso, el Supremo Tribunal Federal descartó el uso de la expresión "territorio indígena" al reforzar que la categoría "tierra indígena" no debe asumir un carácter político-territorial (ARAUJO JÚNIOR, 2018, p. 231).

La cautela cuanto al reconocimiento de la autodeterminación de los pueblos indígenas se deriva del hecho de que en otros pactos internacionales - por ejemplo, el Pacto Internacional sobre Derechos Económicos, Sociales y Culturales de las Naciones Unidas - que en su artículo primero, párrafo 1 establece que todos los pueblos tienen derecho a la autodeterminación y que, en virtud de ese derecho, determinan libremente su estatuto político y aseguran libremente su desarrollo económico, social y cultural -, los términos pueblos y autodeterminación se emplearon como sinónimo de independencia. Sin embargo, esos otros pactos, al abordar la autodeterminación de los pueblos, se referían a una realidad histórica concreta, como era la de los territorios coloniales de las grandes potencias, relacionándolo, por lo tanto, al fenómeno de la descolonización.

De su parte, la Declaración de las Naciones Unidas sobre los Derechos de los Pueblos Indígenas se refiere a la autodeterminación interna de los pueblos indígenas, que afecta no a la propia soberanía del Estado, sino la forma de organización política y económica interna. De esta forma, más que secesión o independencia política, se habla hoy en día de diversas formas de autonomía política, territorial y económica (CABEDO MALLOL, 2002, p. 53-54; STAVENHAGEN, 2010).

No existe derecho a la soberanía de los pueblos indígenas en virtud de las normas del derecho internacional, que lo excluyen expresamente cuando utilizan el término "pueblos". Sin embargo, la interpretación del término "autodeterminación" en los textos internacionales ha sido como "la validez del derecho consuetudinario interno y la participación política de los pueblos indígenas en las decisiones que les afectan, no como una reivindicación de soberanía" (CUNHA, 1994, p. 130).

La autodeterminación, entonces, asume un nuevo aspecto relacional, en el que los grupos se autodeterminan, pero mantienen continuas relaciones con los Estados, como señala Ikawa, para quien "La idea relacional de autodeterminación, que puede entablar puntos de contacto con los derechos humanos, se está aplicando en un número cada vez mayor de Estados, como Canadá, Nueva Zelanda, Dinamarca, México, Guatemala, Colombia, Filipinas, entre otros." (IKAWA, 2010, p. 507). 
La naturaleza de derechos colectivos se explica porque esos derechos afectan a una colectividad, a un grupo étnico, en suma: a un pueblo. El concepto de pueblo indígena, sin embargo, sufre alto grado de indefinición, propio de un término con una función semántica abierta. Hay en la Convención 169 de la OIT tres criterios para la identificación de los pueblos a los que se aplica: la existencia de condiciones sociales, culturales y económicas diferentes de otros sectores de la sociedad nacional; la presencia de una organización social conducida total o parcialmente por reglas y tradiciones propias; y la autoidentificación, comprendida como la conciencia que tiene el grupo social de su identidad tribual (artículo 1). Entre esos parámetros, la conciencia de su identidad indígena o tribal es el criterio fundamental para determinar los grupos a que se destinan las disposiciones de la Convención. Aunque no exista una definición jurídica concluyente, el uso del término pueblo indígena expresa "la idea de una identidad indígena colectiva propia." (KAYSER, 2010, p. 41). La efectividad del concepto, por lo tanto, debe aseverar elementos extrajurídicos, oriundos de la antropología.

\section{LA BAJA EFECTIVIDAD DEL MODELO FUNDADO EN EL MULTICUL- TURALISMO LIBERAL}

Los derechos colectivos de los pueblos indígenas, por cierto, no anulan los derechos individuales de los indígenas, ya que tanto éstos como los derechos colectivos son derechos humanos y se complementan mutuamente (STAVENHAGEN, 2000). Este aspecto instiga la delicada cuestión del conflicto entre el derecho indígena y la proclamada universalización de los derechos humanos. Souza Filho (2001, p. 253-261) defiende el universalismo parcial de los derechos humanos, que sea capaz de acoger lo que el referido autor denomina de "jusdiversidad", es decir, el reconocimiento del derecho y de la jurisdicción indígena. Fundamentalmente, este debate se refiere a los límites del multiculturalismo liberal.

El liberalismo político, basado en la capacidad de autodeterminación de los individuos para la elección de la buena vida (autonomía), resulta en un modelo de acción colectiva en que los derechos individuales se superponen a las diferencias culturales. El multiculturalismo, al rechazar la imparcialidad y el universalismo, se opone a esa visión de sociedad liberal autonomista, para proponer una concepción en que el pluralismo es un valor a ser seriamente considerado en el momento de fijación de los principios de justicia.

Kymlicka (2009, p. 75) apunta que el objetivo mayor de crítica del multiculturalismo es la homogeneidad del Estado nación, que marginaliza y estigmatiza a las minorías culturales existentes dentro del territorio. Sin embargo, el multiculturalismo no resulta en el rechazo de la existencia de un rol de derechos fundamentales, que pueden preponderar sobre las identidades culturales. Lo que ocurre es que las sociedades multiculturales "se disponen a sopesar la importancia de ciertas formas de trato uniforme con relación a la importancia de la supervivencia cultural, y optar a veces por esta última" (TAYLOR, 2000, p. 266). De hecho, uno de los criterios para verificar el éxito de las políticas multiculturales es la previ- 
sible fuerza de atracción de las estructuras liberales sobre las fronteras étnicas y culturales, es decir, el acomodamiento de la diversidad étnico-cultural a los límites de los derechos humanos (KYMLICKA, 2009, p. 152 y 165).

Las características del multiculturalismo conducen a grandes paradojas. Kymlicka (2009, p. 167-168) sugiere la concesión de capacidad legislativa a los miembros de la comunidad indígena para reformar su derecho consuetudinario, por medio de un proceso democrático, como forma de solucionar el conflicto entre la autonomía étnico-cultural y el respeto a los derechos humanos. Este conflicto ha generado una abundante jurisprudencia multicultural internacional, según relata Silva (2010, p. 590-594). Las autoridades judiciales de las sociedades multiculturales, al considerar la autonomía de las comunidades indígenas y los derechos individuales, han considerado inaceptable el esencialismo étnico y el extremo relativismo cultural. Estas soluciones, al final, acaban por negar el derecho a la diferencia cultural a las sociedades que no se ajustan en el patrón democrático-liberal. De esta forma, según destaca Yrigoyen Fajardo (2011, p. 141), bajo el signo del multiculturalismo liberal, la diversidad cultural se ha convertido en fundamento, pero también en límite para el reconocimiento del derecho indígena.

Cabedo Mallol (2004, p. 35-41) resalta que el relativismo cultural moderado, en que se basa la visión multicultural liberal, sólo afirma, de modo velado, la pretendida universalidad de los derechos humanos. Sin embargo, los derechos humanos son particulares (y no universales), en el sentido de que son construcciones dependientes del contexto histórico y cultural en el que se reproducen. Así, la falsa universalidad de los valores de una cultura particular (la occidental) traduce la imposición o incluso la dominación de una cultura sobre otra. Aunque sean particulares, los derechos humanos tienen propensión a la universalidad, que debe promoverse mediante la búsqueda de valores transculturales. La propuesta del autor es que sólo un diálogo intercultural franco, no coercitivo, basado en el intento de comprender la visión del mundo del otro y que sea mutuamente enriquecedor, puede construir una cultura de los derechos humanos que atiendan las particularidades económicas, sociales étnicas y culturales de los diversos pueblos.

El salto más allá del paradigma multicultural se debe a las recientes experiencias constitucionales latinoamericanas. En este contexto, surge el nuevo concepto de interculturalidad, utilizado para designar un proyecto político de construcción de relaciones entre grupos étnicos, destinadas a confrontar y transformar las relaciones de poder basadas en el modelo colonial y eurocéntrico, así como de modificar las instituciones que mantienen y naturalizan las desigualdades sociales (WALSH, 2015, p. 346-347). La profundización de los derechos étnicos resultó en el reconocimiento del Estado plurinacional, en el que los diversos pueblos, incluidos los indígenas, son elevados a la condición de sujetos constituyentes de la nación. Destaca Oliveira Filho que "La plurinacionalidad es un proyecto local que parte de la agenda del multiculturalismo para superarlo." (OLIVEIRA FILHO, 2016, p. 83).

En Brasil no hay avances institucionales y normativos significativos para trascender el paradigma del multiculturalismo liberal. En realidad, destaca Beckhausen (2010, p. 525- 
557), incluso el régimen de tolerancia multicultural es aún fragilizado institucionalmente. De igual manera, según lo explicó Wolkmer $(2015$, p. 285), la Constitución brasileña de 1988 representó un innegable marco histórico en el reconocimiento de los derechos de los pueblos indígenas.

\section{LAS RESISTENCIAS AL RECONOCIMIENTO DE LA EXISTENCIA DEL DERECHO INDÍGENA}

El término derecho indígena debe ser comprendido como los medios de autorregulación y autorresolución de los conflictos internos de los pueblos indígenas, es decir, el "derecho consuetudinario interno de las comunidades indígenas” (KAYSER, 2010, p. 295-296). Por su parte, la expresión jurisdicción indígena designa la aplicación y ejecución de ese derecho por los miembros del propio pueblo indígena (CABEDO MALLOL, 2002, p. 77). El derecho es una parte fundamental de la cultura de un pueblo, luego, el derecho indígena debe ser comprendido dentro del contexto más amplio de las costumbres indígenas. El adjetivo indigena a calificar ese derecho es empleado de forma general, lo que no significa la defensa de una homogeneidad entre los varios pueblos indígenas.

La socio-diversidad de los pueblos indígenas es desconocida del público en general de Brasil, y Ricardo afirmó que "No se sabe con certeza ni cuántos pueblos ni cuántas lenguas nativas existen. El (re) conocimiento, aunque parcial, de esa diversidad, no supera los estrictos círculos académicos especializados." (RICARDO, 2001, p. 65). Así, una mirada más cuidadosa puede revelar la existencia de un derecho Guaraní, Ticuna, Makuxi, Yanomami, Kayapó, etc. El tratamiento generalizado se justifica sólo porque en el presente artículo discutimos el posicionamiento del ordenamiento jurídico estatal frente a los diversos derechos indígenas y no un abordaje específico de las normas consuetudinarias que componen estos derechos alternativos.

Las costumbres jurídicas indígenas son descritas por Herrera Ortiz como:

$$
\begin{aligned}
& \text { aquellos actos u omisiones realizados por los individuos que integran un grupo } \\
& \text { étnico dentro de su comunidad, de una manera reiterada y constante, de tal } \\
& \text { forma que llegan a ser parte de su vida cotidiana y se les considera como jurí- } \\
& \text { dicamente obligatorios, teniendo como finalidad ejercer el control social, pero } \\
& \text { sin estar escritos ni codificados, cuya infracción o incumplimiento provoca la } \\
& \text { aplicación de sanciones, mediante correctivos económicos, laborales, corporales } \\
& \text { o sociales, impuestos al infractor por las autoridades tradicionales de lugar o por } \\
& \text { la autoridad estatal que opera dentro de la comunidad desconociendo, ignoran- } \\
& \text { do, contraviniendo o concibiendo en su caso, algo diferente a lo establecido en } \\
& \text { la legislación vigente creada por el estado (HERRERA ORTIZ, 1996, p. 57). }
\end{aligned}
$$

No hay una distinción rigurosa entre la esfera jurídica y otros campos de la vida social indígena, como el religioso, el económico y el político (BARRERA HERNÁNDEZ, 1995, p. 175-176). Así, partiendo de la noción de que el derecho es sólo parte de la experiencia normativa (BOBBIO, 2008, p. 5; NINO, 2010, p. 118), se puede preferir el término sistema 
normativo para referirse al derecho indígena, debido a la ausencia de una evidente separación entre derecho y moral. Villares prefiere el uso del término sistema normativo, al apuntar que "lo que se llama el derecho es un sistema normativo específico, creación de un período histórico, la modernidad, para lo cual la existencia del Estado es imprescindible" (VILLARES, 2009, p. 22). Sin embargo, el autor reconoce que los sistemas normativos indígenas ejercen verdaderas funciones de sistemas jurídicos.

La distinción entre "sistema normativo" de un lado y "derecho" de otro, para restringir el uso de este último término sólo a la manifestación del Estado moderno, resulta en una actitud idealista-universalista en la explicación del fenómeno jurídico. De hecho, si las instituciones jurídicas son apreciadas sólo a partir del derecho occidental moderno, otros sistemas jurídicos, como los indígenas y tribales, corren el riesgo de ser tratados como caricaturas jurídicas (MIAILLE, 2005, p. 54).

Por lo tanto, debemos utilizar sin restricciones la expresión derecho indigena para designar las costumbres jurídicas de los pueblos indígenas. El hecho de que este derecho no sea una creación estatal no es un criterio suficiente para negar su existencia y su naturaleza de ordenamiento jurídico. Rocha $(2008$, p. 45) aclara que se trata sólo de un derecho institucionalizado por otras formas, diversas de la estatal.

La limitación del concepto de derecho sólo a las manifestaciones estatales expresa una concepción propia, denominada en la teoría del derecho de monismo jurídico. En resumen, por "monismo", se puede comprender la idea de atribuir al Estado "el monopolio de la producción de las normas jurídicas, o sea, la idea de que el Estado es el único agente legitimado capaz de crear legalidad para encuadrar las formas de relaciones sociales que se van imponiendo" (WOLKMER, 2001, p. 46). La teoría monista identifica el Derecho con el Estado: el Derecho sólo se realiza por medio del Estado (carácter coercitivo del Derecho); y el Estado se materializa por medio del Derecho (Estado formal de Derecho).

El monismo es el producto de un proceso histórico de disolución de la sociedad medieval, por medio de la eliminación o absorción de los ordenamientos jurídicos superiores e inferiores a la sociedad nacional, que llevó a la formación del Estado moderno (BOBBIO, 2008 , p. 11). La teoría monista es ineficaz para tratar el valor constitucional del pluralismo étnico. Esta constatación es aún más evidente ante posibles incompatibilidades entre el ordenamiento estatal y el ordenamiento indígena. Aunque el derecho indígena es un derecho alternativo, no tiene carácter subversivo, ya que su plena eficacia no pone en peligro el sistema hegemónico (CABEDO MALLOL, 2002, p. 67).

El pluralismo jurídico, a su vez, rompe con la idea de monopolio estatal en la producción del Derecho y admite la coexistencia de ordenamientos jurídicos en un mismo ámbito espacial, originados por fuentes no estatales. En contraste al monismo, el pluralismo jurídico comprende un conjunto variado de posiciones teóricas, cuyo núcleo principal converge hacia el rechazo del dogma de que el Estado consistiría en la fuente única y exclusiva de todo el Derecho (WOLKMER, 2001, p. 46). 
El debate sobre el pluralismo jurídico resurge de la crisis del Estado Liberal y de la transición al Estado Social a partir de la proliferación de grupos (sindicatos, asociaciones civiles, partidos, corporaciones, entidades religiosas, etc.) intermediarios entre el Estado y el individuo (BOBBIO, 2010, p. 929-930).

El pluralismo jurídico asumió nuevas formulaciones contemporáneas en diversas vertientes, tales como la defensa de una pluralidad policéntrica e infra-jurídica; el pluralismo resultante de fenómenos multiétnicos y multiculturales propios de sociedades marcadas por brotes migratorios; el pluralismo jurídico mercantil; y el pluralismo de las prácticas participativas comunitarias (WOLKMER, 2009, p. 638-639). Los ciclos de reformas constitucionales latinoamericanas, desde los años 1990, pero especialmente a partir de la primera década de los años 2000, ampliaron la acogida del pluralismo jurídico en temas de derechos étnicos y culturales que involucra a los pueblos indígenas originarios (YRIGOYEN FAJARDO, 2015, p. 38-47).

Así, el pluralismo jurídico se presenta como una teoría más adecuada para explicar la juridicidad del derecho indígena (BONILLA MALDONADO, 2007; ROMANO, 1917). Una comunidad indígena es un ente de existencia concreta, de naturaleza social, que puede ser examinada en sí misma y que no se confunde con sus miembros. Una comunidad indígena es, en resumen, una unidad social organizada; y como tal, produce un ordenamiento jurídico. La naturaleza jurídica de ese ordenamiento es independiente de su plena eficacia ante el ordenamiento estatal, abriéndose el campo de investigación sobre las formas por las cuales la institución comunidad indígena y la institución Estado se coordinan. La relevancia de un ordenamiento para el otro se verifica en la apertura del Estado Constitucional al valor del pluralismo étnico y por el abandono de la política integracionista. En otras palabras, asegurar la efectividad del ordenamiento indígena es atender a un dictamen del propio ordenamiento estatal.

La búsqueda por la coordinación entre el ordenamiento estatal y el derecho consuetudinario indígena fue reconocida por primera vez en América Latina por la Constitución Política de Colombia de 1991, en su artículo 2466. Sin embargo, destacan Herrán Pinzón y García Hernández que

La jurisdicción especial indígena es la manifestación de la autonomía jurídica y política que se le reconoce a las comunidades indígenas el ejercicio de esta jurisdicción no está condicionada ni se puede condicionar a una ley que la habilite es decir no es requisito esencial que exista una ley de coordinación entre los dos sistemas (HERRÁN PINZÓN; GARCÍA HERNÁNDEZ, 2010, p. 40).

Por su parte, el interculturalismo crítico, como resalta Walsh (2015, p. 350), cuestiona la relación jerárquica entre los ordenamientos y apuntando a la necesidad de que el pluralismo jurídico sea comprendido como parte del proyecto político de refundación del Estado.

6 "Artículo 246. Las autoridades de los pueblos indígenas podrán ejercer funciones jurisdiccionales dentro de su ámbito territorial, de conformidad con sus propias normas y procedimientos, siempre que no sean contrarios a la Constitución y leyes de la República. La ley establecerá las formas de coordinación de esta jurisdicción especial con el sistema judicial nacional." 


\section{EL RECONOCIMIENTO DEL DERECHO INDÍGENA Y EL EJERCICIO DE SU JURISDICCIÓN}

La autodeterminación interna de los pueblos indígenas comprende el derecho de los pueblos indígenas al mantenimiento de sus propias formas de administración comunitaria y de organización conforme a sus tradiciones. Es en el ámbito de ese derecho que se inserta el reconocimiento del derecho indígena y el ejercicio de funciones jurisdiccionales por parte de las autoridades indígenas.

No hay en la Constitución brasileña de 1988 una disposición específica sobre el derecho y la jurisdicción indígena. Otros textos constitucionales de países iberoamericanos optaron por el reconocimiento expreso del derecho indígena y del ejercicio de la jurisdicción en él basada por las propias autoridades indígenas.

Yrigoyen Fajardo (2011, p. 139-159) relata la existencia de tres ciclos de reformas constitucionales sobre el tema. El primer ciclo representó el constitucionalismo multicultural, de 1982 a 1988 y fue caracterizado por la emergencia del derecho a la diversidad cultural, en las bases del multiculturalismo, en que son ejemplos las Constituciones de Canadá (1982), de Guatemala (1985), de Nicaragua (1987) y de Brasil (1998). El segundo ciclo, de 1989 a 2005, despunta el constitucionalismo pluricultural, en que se acogió la noción de Estado plurinacional, siendo ejemplos las Constituciones de Colombia (1991), de México (1992), del Paraguay (1992), del Perú (1993), de Bolivia (1994 y 2004), de Argentina (1994), de Ecuador (1998) y de Venezuela (1999), mientras que el tercer ciclo, de 2006 a 2009, asistió al proyecto del pluralismo jurídico igualitario, de que son ejemplos las Constituciones de Bolivia (2006 y 2009) y de Ecuador (2008).

Las Constituciones latinoamericanas, a partir de los años 1990, expresamente pluralizaron las fuentes de producción jurídica. Estas Constituciones reconocieron el ejercicio de la jurisdicción por las autoridades indígenas para resolver conflictos de acuerdo con sus propias normas y procedimientos de su derecho consuetudinario. Algunos países, como Bolivia y Ecuador, profundizaron el reconocimiento de los derechos étnicos, abandonaron el propio paradigma del multiculturalismo liberal y construyeron una nueva noción de plurinacionalidad. El Estado Plurinacional busca una salida para las sociedades multiétnicas, "a partir de las experiencias interculturales, reconociendo nuevas fuentes de producción de Derecho: al lado de la jurisdicción ordinaria, pasa a ser considerada la jurisdicción originaria, indígena o campesina, sus autoridades, instituciones, prácticas y las costumbres" (OLIVEIRA FILHO, 2016, p. 81-84). En este nuevo paradigma, los pueblos indígenas no son sólo culturas diferentes a ser reconocidas, sino que, además, son un sujeto político colectivo y autodeterminado que constituye el Estado plurinacional.

La ausencia de referencia explícita en la Constitución brasileña no es obstáculo al reconocer el derecho indígena a partir del valor constitucional del pluralismo étnico.

Al reconocer a los indios su organización social, costumbres y tradiciones la Constitución 
brasileña de 1988 acoge el derecho consuetudinario indígena - pues integrante del concepto de costumbre -, así como el ejercicio de la jurisdicción indígena - integrante del concepto de organización social. El derecho debe entenderse como un sistema de regulación social y resolución de conflictos, participante de la propia identidad cultural de un pueblo. Siendo la identidad cultural un derecho colectivo de los pueblos indígenas, el sistema constitucional debe converger para la acogida de la racionalidad propia de esos pueblos para concebir el orden, la seguridad, la igualdad y la justicia (CABEDO MALLOL, 2002, p. 64).

Villares (2009, p. 293) sostiene que la Constitución, al reconocer las formas de organización indígena, acogió tanto los sistemas jurídicos indígenas como sus autoridades y sus procedimientos. De hecho, el mandamiento constitucional no se cumpliría plenamente sólo con la aplicación del derecho consuetudinario indígena por autoridades estatales. El ejercicio de la jurisdicción por la propia comunidad es un elemento esencial para permitir que los pueblos indígenas se organicen conforme sus tradiciones. El propio Estatuto del Indio (Ley 6.001 de 1973), aunque marcado por el proyecto integracionista, ya reconoce en su artículo 57 la jurisdicción indígena, al tolerar "la aplicación, por los grupos tribales, de acuerdo con las instituciones propias, de sanciones penales o disciplinarias contra sus miembros".

Las insuficiencias del Estatuto del Indio en el reconocimiento del derecho indígena, sobre todo en cuanto a la utilización de la expresión "tolerada" contenida en el artículo 57 de la Ley 6.001/73, indicando un estado de aceptación transitoria, se encuentran superadas por el abandono del proyecto integracionista, tanto por la Constitución de 1988 y por las normas de Derecho Internacional Público (KAYSER, 2010, p. 295-296). Souza Filho señala que dicho artículo 57 del Estatuto del Indio "revela una carga de intolerancia y autorreferencia cultural sin límites” (SOUZA FILHO, 2010, p. 485).

La Convención 169 de la OIT, a su vez, establece el derecho de los pueblos indígenas y tribales de conservar sus costumbres e instituciones, debiendo respetar los métodos a los que estos pueblos recurren tradicionalmente para la represión de los delitos cometidos por sus miembros, a la medida en que ello sea compatible con el sistema jurídico nacional y con los derechos humanos internacionalmente reconocidos, imponiéndose, además, que se tengan en cuenta, al aplicarse la legislación nacional a los pueblos indígenas y tribales, sus costumbres o su derecho consuetudinario (artículos 8,9 y 10). Es de notar que el reconocimiento del derecho consuetudinario indígena ya constaba en la anterior Convención 107 de la OIT, en que pese la salvedad de que ese reconocimiento no podría ser incompatible también con los objetivos de integración (artículo 7).

También la Declaración de las Naciones Unidas sobre los Derechos de los Pueblos Indígenas reconoce el derecho de los pueblos indígenas a la autonomía o autogobierno en las cuestiones relacionadas con sus asuntos internos (artículo 4), también se les resguarda el derecho de conservar y reforzar sus propias instituciones políticas, económicas, sociales y culturales (artículo 5).

Luego, desde el punto de vista normativo, incluso el paradigma del multiculturalismo liberal 
que atraviesa la Constitución brasileña de 1988 es suficiente para el reconocimiento del derecho y de la jurisdicción indígena. Sin embargo, según destaca Villares (2009, p. 296), el aparato judicial brasileño todavía ignora la jusdiversidad producida por los sistemas normativos indígenas.

La falta de aceptación de la jusdiversidad de los pueblos indígenas no es el resultado de una simple ignorancia de la adecuación de las normas constitucionales al pluralismo jurídico. Al contrario, es la expresión de una "hermenéutica que asocia a los pueblos indígenas con el grado de civilización, una postura claramente colonial de construcción e identidad nacional" (BALDI, 2017, p. 261).

Esta realidad es revelada por el caso ocurrido en Brasil, en la comunidad Manoa/Pium, en el cual hubo la manifestación explícita de un Tribunal de Justicia estadual sobre el deber del Estado en reconocer el derecho indígena. En diciembre de 2016, el Tribunal de Justicia del Estado de Roraima juzgó la Apelación Criminal n o 090.10.000302-0, en la que declaró la ausencia del derecho de castigar al Estado frente a un indígena, acusado de homicidio practicado contra otro miembro de su familia étnica, en la tierra indígena de Manoá/Pium, Región Serra da Lua, municipio de Bonfim, estado de Roraima. Los miembros del consejo de la comunidad indígena aplicaron al indio la obligación de reparar la viuda de la víctima y el desplazamiento obligatorio y provisional a otra comunidad, además de otras sanciones tradicionales, destituidas de carácter cruel o atentatorio a los derechos humanos. Sin embargo, el órgano de acusación penal presentó denuncia contra el indio y posteriormente apeló contra la absolución en primera instancia, bajo la alegación de transgresión al monopolio de la acción penal pública incondicional y violación del principio de que la jurisdicción no puede excluirse. El Tribunal de Justicia de Roraima mantuvo la absolución, con fundamento en el derecho humano que prohíbe el bis in idem, también por reconocer el deber jurídico del Estado brasileño en garantizar la autodeterminación de la comunidad indígena para componer sus conflictos internos, con base en el artículo 231 de la Constitución de la República, en el Estatuto del Indio y en el Convenio 169 de la OIT, internalizado por el Decreto 5.051/2004 (RORAIMA, 2016).

El caso de la comunidad Manoa/Pium causa gran perplejidad, no por su contenido jurídico-normativo, pero por lo que revela de la historia de las instituciones. Pasados más de cuarenta años del Estatuto del Indio, tanto la sentencia de absolución y la decisión del Tribunal de Apelación reconocieron la ausencia de precedentes en la jurisdicción brasileña sobre el tema. A pesar de que las decisiones judiciales aisladas que acogían el derecho indígena se habían ocurrido - y ciertamente ocurrieron, como noticia Barreto (2010, p. 119120) acerca de la absolución de indígena de la comunidad Maturuca, de la acusación por el crimen de homicidio practicado en 1986 contra otro indígena, por decisión del Tribunal de Jurado Federal de la $2^{\text {a }}$ Vara Federal de Roraima, ocurrido en el año 2000, que reconoció causa supralegal de exclusión de culpabilidad en el hecho de que el acusado ya fue juzgado y condenado por su comunidad indígena - esas excepciones sólo confirman la regla de la ausencia de una política judicial brasileña sensible al pluralismo étnico acogido por la Constitución de la República, aunque en base multiculturalista-liberal. 
La ausencia de efectividad del reconocimiento del derecho y de la jurisdicción indígena es el resultado de una dificultad de abandono de los patrones integracionistas, eurocéntricos y monistas en que las instituciones jurídicas brasileñas fueron forjadas.

\section{CONCLUSIONES}

En Brasil, las comunidades indígenas enfrentan desafíos excesivamente complejos para garantizar su supervivencia física y cultural. Los problemas mucho más evidentes - como la demora en la demarcación de tierras, la explotación ilegal de recursos naturales en áreas indígenas, el riesgo a la preservación ambiental, la insuficiencia en la asistencia a la salud, el menosprecio al derecho a la consulta previa sobre cuestiones que afecten directamente a las comunidades indígenas, la violencia contra liderazgos indígenas, la desprotección al conocimiento tradicional - pueden relegar a un segundo plan la discusión sobre el deber del reconocimiento por el Estado brasileño del derecho consuetudinario indígena y el ejercicio de su jurisdicción por las propias comunidades. Sin embargo, la falta de respeto a este deber es una forma de violencia no sólo simbólica, sino también real.

Los individuos pertenecientes a los pueblos indígenas son, evidentemente, titulares de los derechos consagrados en la Declaración Universal de los Derechos Humanos. Por otra parte, son víctimas de grandes violaciones a los derechos de la persona humana, practicadas por los Estados Nacionales y por agentes privados movidos por intereses económicos. Sin embargo, una comprensión exclusivamente individualista de los derechos humanos, fundada en el paradigma de la sociedad liberal, puede dar lugar a la violación de los derechos colectivos de los pueblos indígenas.

A partir de un pasado colonial, del etnocidio del Estado nación del siglo XIX y de la política integracionista del siglo XX, caminamos en Brasil, después de la Constitución de 1988, hasta un nivel de reconocimiento del pluralismo étnico, de base multicultural, pero aún de baja efectividad e inacabado. No logramos seguir el camino del pluriculturalismo, ya diseminado en las Constituciones latinoamericanas que expresamente reconocen el pluralismo jurídico y mucho menos seguimos los pasos de la experiencia del Estado plurinacional.

Las instituciones jurídicas brasileñas todavía resisten en reconocer la existencia del derecho indígena y la posibilidad de que los conflictos sobre su aplicación sean resueltos por las propias comunidades indígenas. Esta resistencia asume una forma de imposición unilateral de la visión de mundo occidental, resultando en un retroceso integracionista incompatible con el parámetro del pluralismo étnico, acogido por la Constitución brasileña de 1988. Esa postura debe, por lo tanto, ser superada, ya que, como se ha demostrado a lo largo del presente artículo, hay suficiente demarcación jurídica - pactos internacionales debidamente internalizados, normas constitucionales y legales - y doctrinal para la acogida del derecho indígena y también para el reconocimiento del ejercicio de su jurisdicción por las autoridades indígenas. 


\section{REFERÊNCIAS}

ACCIOLY, Hildebrando; SILVA, G. E. do Nascimento; CASELLA, Paulo Borba. Manual de Direito Internacional Público. 17. ed. São Paulo: Saraiva, 2009.

ARAUJO JÚNIOR, Julio José. Direitos Territoriais Indígenas: uma interpretação intercultural. Rio de Janeiro: Processo, 2018.

BALDI, César Augusto. Questão indígena no Brasil: alguns pontos para uma revisão hermenêutica da jurisprudência do Supremo Tribunal Federal. In: AVRITZER, Leonardo; GOMES, Lilian Cristina Bernardo; MARONA, Marjorie Corrêa; DANTAS, Fernando Antônio de Carvalho (org.). O constitucionalismo democrático latino-americano em debate: soberania, separação de poderes e sistema de direitos. Belo Horizonte: Autêntica, 2017. p. 253-285.

BARRERA HERNÁNDEZ, Abel. Ritualidad y poder entre los nahuas de la montaña de Guerrero. In: ESTRADA MARTÍNEZ, Rosalba Isabel; GONZÁLEZ GUERRA, Gisela (coord.). Tradiciones y costumbres jurídicos en comunidades indígenas de México. México: Comisión Nacional de Derechos Humanos, 1995.

BARRETO, Helder Girão. Direitos Indígenas: vetores constitucionais. Curitiba: Juruá, 2010. BARTOLOMÉ, Miguel Alberto; BARABAS, Alicia. Autonomías Étnicas y Estados Nacionales. México, D.F.: Consejo Nacional para la Cultura y las Artes: Instituto Nacional de Antropología e Historia, 1998.

BECKHAUSEN, Marcelo. Etnocidadania, direitos originários e a inconstitucionalidade do poder tutelar. In: SARMENTO, Daniel; IKAWA, Daniela; PIOVESAN, Flávia. Igualdade, Diferença e Direitos Humanos. Rio de Janeiro: Lumen Juris Editora, 2010. p. 525-557.

BOBBIO, Norberto. Teoria Geral do Direito. 2. ed. São Paulo: Martins Fontes, 2008.

BOBBIO, Norberto. Pluralismo. In: BOBBIO, Norberto; MATTEUCCIO, Nicola; PASQUINO, Gianfranco. Dicionário de política. 13. ed. Brasília: Universidade de Brasília, 2010. v. 2. BONILlA MALDONADO, Daniel et al. Pluralismo jurídico. Bogotá: Siglo del Hombre Editores, Universidad de los Andes, Pontificia Universidad Javerina, 2007.

BRASIL. [Constituição (1988)]. Constituição da República Federativa do Brasil de 1988. Brasília, DF: Presidência da República, 1988. Disponível em: http://www.planalto.gov.br/ ccivil_03/constituicao/constituicao.htm. Acesso em: 1 jan. 2018.

BRASIL. Supremo Tribunal Federal. Tribunal Pleno. Petição 3.388/RR. Relator: Ministro Carlos Ayres Britto. Brasília, 19 de março de 2009. Revista Trimestral de Jurisprudência, v. 212, p. 49-371, abr.jun. 2010.

BRASIL. Supremo Tribunal Federal. Tribunal Pleno. Recurso Extraordinário 466.343/SP. Relator: Ministro Cezar Peluso. Brasília, 03 de dezembro de 2008. Revista Trimestral de 
Jurisprudência, v. 210, n. 2, p. 745-863, out./dez. 2009.

BRUNN, Reinhild Margarete von. Metamorfosis y desaparición del vencido: desde la subalternidad a la complementariedad en la imagen de Santiago ecuestre en Perú y Bolivia. 2009. 284 f. Tesis (Magíster en Artes con mención en Teoría e Historia del Arte) - Universidad de Chile, Facultad de Artes, Escuela de Postgrado, Santiago de Chile, 2009.

CABEDO MALLOL, Vicente. Análisis de las Constituciones políticas latinoamericanas: regulación constitucional del derecho indígena en Iberoamérica. In: PEÑA JUMPA, Antonio; CABEDO MALLOL, Vicente; LÓPEZ BÁRCENAS, Francisco. Constituciones, Derecho y Justicia en los Pueblos Indígenas de América Latina. Lima, Perú: Fondo Editorial de la Pontificia Universidad Católica del Perú, 2002.

CABEDO MALLOL, Vicente. Constitucionalismo y derecho indígena en América Latina. Valencia: Universidad politécnica de Valencia Editorial, 2004.

CUNHA, Manuela Carneiro da. O futuro da questão indígena. Estudos Avançados, São Paulo, v. 8, n. 20, p. 121-136, abr. 1994.

DANTAS, Fernando Antônio de Carvalho. Entre a nação imaginada e o estado plurinacional: o reconhecimento dos direitos indígenas no novo constitucionalismo latino-americano. In: AVRITZER, Leonardo; GOMES, Lilian Cristina Bernardo; MARONA, Marjorie Corrêa; DANTAS, Fernando Antônio de Carvalho (org.). O constitucionalismo democrático latino-americano em debate: soberania, separação de poderes e sistema de direitos. Belo Horizonte: Autêntica, 2017. p. 213-230.

HERRÁN PINZÓN, Omar Antonio; GARCÍA HERNÁNDEZ, Guillermo. Identidad judicial indígena frente a la jurisdicción ordinaria actual en Colombia. Prolegómenos - Derechos y Valores, Bogotá, v. 13, n. 26, p. 29-42, jul./dic. 2010.

HERRERA ORTIZ, Margarita. Costumbre indígena jurídica en el Estado de Veracruz. México: Editora del Gobierno del Estado de Veracruz, 1996.

ILO. INTERNATIONAL LABOUR ORGANIZATION. NORMLEX. Ratification of C169 - Indigenous and Tribal Peoples Convention, 1989 ( $\mathrm{N}^{\circ}$ 169). Disponível em: https://www. ilo.org/dyn/normlex/en/f?p=1000:11300:0::NO:11300:P11300_INSTRUMENT_ID:312314. Acesso em: 27 maio 2019.

IKAWA, Daniela. Direito dos Povos Indígenas. In: SARMENTO, Daniel; IKAWA, Daniela; PIOVESAN, Flávia. Igualdade, Diferença e Direitos Humanos. Rio de Janeiro: Lumen Juris, 2010. p. 497-524.

KAYSER, Hartmut-Emanuel. Os direitos dos povos indígenas do Brasil: desenvolvimento histórico e estágio atual. Porto Alegre: Sergio Antonio Fabris Ed., 2010.

KYMLICKA, Will. Las odiseas multiculturales: Las nuevas políticas internacionales de la diversidad. Barcelona: Paidós, 2009. 
LEIVAS, Paulo Gilberto Cogo; RIOS, Roger Raupp; SCHÄFER, Gilberto; SARTORI JÚNIOR, Dailor. Direitos Fundamentais Coletivos de Povos Indígenas e Comunidades Tradicionais. Revista Culturas Jurídicas, Niterói, v. 4, n. 8, p. 314-331, maio/ago. 2017.

LIMA, Antônio Carlos de Souza. O Governo dos Índios sob a gestão do SPI. In: CUNHA, Manuela Carneiro da. (org.). História dos índios no Brasil. São Paulo: Companhia das Letras, 1992. p. 155-172.

LOPES, Ana Maria D’Ávila. Proteção constitucional dos direitos fundamentais culturais das minorias sob a perspectiva do multiculturalismo. Revista de Informação Legislativa. Brasília, ano 45, n. 177, p. 19-29, jan./mar. 2008.

MIAILLE, Michel. Introdução crítica ao Direito. 3. ed. Lisboa: Editorial Estampa, 2005. NINO, Carlos Santiago. Introdução à análise do Direito. São Paulo: Editora WMF Martins Fontes, 2010.

OEA. Comisión Interamericana de Derechos Humanos. Relatoría sobre los Derechos de los Pueblos Indígenas. Derechos de los Pueblos Indígenas. Disponível em: http://www.oas.org/ es/cidh/indigenas/default.asp. Acesso em: 28 out. 2017.

OEA. Asamblea General. Declaración americana sobre los derechos de los pueblos indígenas. Santo Domingo, 14 junho 2016.

OLIVEIRA FILHO, Gabriel Barbosa Gomes de. O Estado Plurinacional da Bolívia: as garantias fundamentais à autonomia e autogoverno das autoridades indígenas originário campesinas. 2016. 118 f. Dissertação (Mestrado em Direito Constitucional) - Universidade Federal Fluminense, Faculdade de Direito, Niterói, 2016.

PALMQUIST, Helena; ARAÚJO JUNIOR, Julio José; BOAVENTURA, Luis de Camões Lima; BECKHAUSEN, Marcelo Veiga; ZOLLINGER, Márcia Brandão; OLIVEIRA, Rodrigo Magalhães de. Reminiscências tutelares: a MP 870/2019 e seu projeto inconstitucional para os povos indígenas. Brasília: Ministério Público Federal, 2019. Disponível em: http://www. mpf.mp.br/atuacao-tematica/ccr6/documentos-e-publicacoes/artigos/docs_artigos/artigo-reminiscencias-tutelares-1.pdf. Acesso em: 27 maio 2019.

RICARDO, Carlos Alberto. Passados 500 anos, sequer sabemos seus nomes. In: GRUPIONI, Luís Donisete Benzi; VIDAL, Lux Boelitz; FISCHMANN, Roseli (org.). Povos Indígenas e Tolerância: construindo práticas de respeito e solidariedade. São Paulo: Universidade de São Paulo, 2001. p. 63-70.

ROCHA, José Manuel de Sacadura. Antropologia Jurídica: para uma filosofia antropológica do Direito. Rio de Janeiro: Elsevier, 2008.

RODRIGUES, Cíntia Régia. O Apostolado Positivista do Brasil e o SPILTN: propostas e políticas para a questão indígena no Brasil. Topoi, Rio de Janeiro, v. 20, n. 40, p. 185-203, jan./abr. 2019. 
ROMANO, Santi. L'ordinamento giuridico. Studi sul concetto, le fonti e i caratteri del diritto, Parte prima. Pisa, Italia: Tipogradia editrice cav. Mariotti, 1917.

RORAIMA (Estado). Tribunal de Justiça de Roraima. Câmara Única. Apelação Criminal 0090.10.000302-0. Relator: Desembargador Mauro Campello. Boa Vista, 18 de dezembro de 2015. Diário da Justiça Eletrônico, ano XIX, edição 5683, p. 13-14, 17 fev. 2016.

SCHIER, Paulo Ricardo. Filtragem constitucional: construindo uma nova dogmática jurídica. Porto Alegre: Sergio Antonio Fabris Editor, 1999.

SECRETARIA NACIONAL DE JUSTIÇA; COMISSÃO DE ANISTIA; CORTE INTERAMERICANA DE DIREITOS HUMANOS (org.). Jurisprudência da Corte Interamericana de Direitos Humanos: Direitos dos Povos Indígenas. Brasília: Ministério da Justiça, 2014. v. 2.

SILVA, Paulo Thadeu Gomes da. Direito indígena, direito coletivo e multiculturalismo. In: SARMENTO, Daniel; IKAWA, Daniela; PIOVESAN, Flávia. (coord.). Igualdade, Diferença e Direitos Humanos. Rio de Janeiro: Lumen Juris Editora, 2010. p. 559-598.

SOUZA FILHO, Carlos Frederico Marés de. A essência socioambiental do constitucionalismo latino-americano. Revista da Faculdade de Direito da UFG, Goiânia, v. 41, n.1, p. 197-215, jan./jun. 2017.

SOUZA FILHO, Carlos Frederico Marés de. A Universalidade Parcial dos Direitos Humanos. In: GRUPIONI, Luís Donisete Benzi; VIDAL, Lux Boelitz; FISCHMANN, Roseli (org.). Povos Indígenas e Tolerância: Construindo Práticas de Respeito e Solidariedade. São Paulo: Universidade de São Paulo, 2001. p. 253-261.

SOUZA FILHO, Carlos Frederico Marés de. O direito de ser povo. In: SARMENTO, Daniel; IKAWA, Daniela; PIOVESAN, Flávia (coord.). Igualdade, Diferença e Direitos Humanos. Rio de Janeiro: Lumen Juris, 2010. p. 475-495.

STAVENHAGEN, Rodolfo. Derechos Humanos de los Pueblos Indígenas. México: Comisión Nacional de Derechos Humanos, 2000.

STAVENHAGEN, Rodolfo. Los Pueblos Originarios: el debate necesario. Buenos Aires: CLACSO; Instituto de Estudios y Formación de la CTA: CTA ediciones, 2010.

TAYLOR, Charles. A política do reconhecimento. In: TAYLOR, Charles. Argumentos filosóficos. São Paulo: Edições Loyola, 2000. p. 241-247.

VILLARES, Luiz Fernando. Direito e povos indígenas. Curitiba: Juruá, 2009.

WALSH, Catherine. Interculturalidad crítica y pluralismo jurídico: reflexiones en torno a Brasil y Ecuador. In: BALDI, César Augusto (coord.). Aprender desde o Sul: Novas constitucionalidades, pluralismo jurídico e plurinacionalidade. Aprendendo desde o Sul. Belo Horizonte: Fórum, 2015. p. 343-358. 
WOLFRUM, Rüdiger. The Protection of Indigenous Peoples in International Law. Heidelberg Journal of International Law, Heidelberg, v. 59, p. 369-382, 1999.

WOLKMER, Antonio Carlos. Constitucionalismo e Pluralismo na Trajetória do Direito Brasileiro. In: BALDI, César Augusto (coord.). Aprender desde o Sul: Novas constitucionalidades, pluralismo jurídico e plurinacionalidade. Aprendendo desde o Sul. Belo Horizonte: Fórum, 2015. p. 253-262.

WOLKMER, Antonio Carlos. Pluralismo Jurídico: fundamentos de uma nova cultura no Direito. 3. ed. São Paulo: Editora Alfa Omega, 2001.

WOLKMER, Antonio Carlos. Pluralismo Jurídico. In: BARRETO, Vicente de Paulo (coord.). Dicionário de filosofia do direito. São Leopoldo: UNISINOS; Rio de Janeiro: Renovar, 2009. p. 638-639.

YRIGOYEN FAJARDO, Raquel Z. El horizonte del constitucionalismo pluralista: del multiculturalismo a la descolonización. In: GRAVITO, César Rodríguez (coord.). El derecho en América Latina: un mapa para el pensamiento jurídico del siglo XXI. Buenos Aires: Siglo Veintiuno, 2011. p. 139-159.

YRIGOYEN FAJARDO, Raquel Z. Pluralismo jurídico y jurisdicción indígena en el horizonte del Constitucionalismo Pluralista. In: BALDI, César Augusto (coord.). Aprender desde o Sul: novas constitucionalidades, pluralismo jurídico e plurinacionalidade. Aprendendo desde o Sul. Belo Horizonte: Fórum, 2015. p. 35-57.

\section{NOTA}

El artículo es el resultado de la importante contribución de todos sus coautores, tanto en la concepción, ejecución e interpretación del estudio, como en la siguiente aportación individual:

a) Eduardo Manuel Val: delimitación del tema; orientación para la investigación doctrinal, jurisprudencial y legislativa; y revisión del contenido y la metodología;

b) Dalton Robert Tibúrcio: concepción teórica del tema; redacción del texto; investigación jurisprudencial, doctrinal y legislativa; recopilación de datos; revisión del texto; y

c) Denise de Almeida Guimarães: investigación doctrinaria y legislativa; recopilación de datos; revisión del texto. 